Check for updates

Cite this: RSC Adv., 2019, 9, 30637

Received 27th July 2019

Accepted 16th September 2019

DOI: $10.1039 / c 9 r a 05835 d$

rsc.li/rsc-advances

\section{Both the mono- and di-anions of ellagic acid are effective inhibitors of the serine $\beta$-lactamase CTX- $\mathrm{M}-15 \dagger$}

\begin{abstract}
Nathan Talbot, ${ }^{a}$ Nicholas T. Powles ${ }^{b}$ and Michael I. Page (iD) *a
Ellagic acid, a $\delta$-lactone with ionisable phenolic residues, is an efficient time-dependent inhibitor of the serine $\beta$-lactamase enzyme CTX-M-15. The $\mathrm{pH}$-dependence of the rate of inhibition shows that both the mono- and di-anionic species of ellagic acid are effective inhibitors, both with second order rate constants of $\sim 1.5 \times 10^{4} \mathrm{M}^{-1} \mathrm{~s}^{-1}$. The structurally similar $\delta$-lactone urolithin $\mathrm{A}$, which lacks the geometrically appropriate phenolic residue, shows only modest inhibitory activity against CTX-M-15. It is proposed that this inhibition by ellagic acid anions involves acylation of the active site serine and that the negative charge on the inhibitor is required for binding to the active site.
\end{abstract}

\section{Introduction}

After over 70 years of clinical use, ${ }^{1} \beta$-lactam antibiotics (penicillins, cephalosporins, and carbapenems) remain the major class of antimicrobial agents, ${ }^{2}$ but the use of these life-saving therapeutics is increasingly compromised by bacterial resistance. ${ }^{3}$ The most important resistance mechanism is the bacterial production of a group of enzymes, the $\beta$-lactamases, which catalyse the hydrolysis of the $\beta$-lactam thus inactivating the antibiotic. These enzymes are grouped into four classes A$\mathrm{D} ; \mathrm{A}, \mathrm{C}$, and D contain an active site serine residue which catalyses hydrolysis of the $\beta$-lactam by nucleophilic attack on the carbonyl carbon leading to the intermediate acylation of the serine residue. ${ }^{4}$ There have been many reports of inactivating serine $\beta$-lactamases (SBLs) by mechanism based inhibitors involving modification of this acylation process. ${ }^{5}$

By contrast the class B enzymes are metallo- $\beta$-lactamases (MBLs) $^{6}$ which employ 1 or $2 \mathrm{Zn}$ ions as part of their catalytic machinery and are distinct mechanistically from the SBLs. ${ }^{7,8}$

Approved SBL inhibitors are usually paired with a $\beta$-lactam antibiotic (BLICs), ${ }^{9}$ such as amoxicillin/clavulanate, ampicillin/ sulbactam, and piperacillin/tazobactam. ${ }^{10}$ These combinations work well against class A $\beta$-lactamases, but are less effective against class $\mathrm{C}$ and $\mathrm{D}$ enzymes. ${ }^{11}$ The inhibitors react with the active site serine nucleophile forming an acyl-enzyme complex that is subject to low turnover rates, resulting in inhibition of the enzyme. ${ }^{12}$ More recently, there has been a development of

${ }^{a}$ Department of Chemistry, University of Edinburgh, Joseph Black Building, David Brewster Road, Edinburgh EH9 3FJ, UK. E-mail: mike.page@ed.ac.uk

${ }^{b}$ Analytical Innovations, Shaw Park, Huddersfield HD5 9AG, UK

$\dagger$ Electronic supplementary information (ESI) available: pH-rate profile for CTX-M-15 catalysed hydrolysis of cephalothin, $\mathrm{pH}$ speciation plot of ellagic acid. See DOI: 10.1039/c9ra05835d non- $\beta$-lactam inhibitors such as avibactam and related bicyclic ureas $^{13}$ and the cyclic boronic vaborbactam. ${ }^{14}$
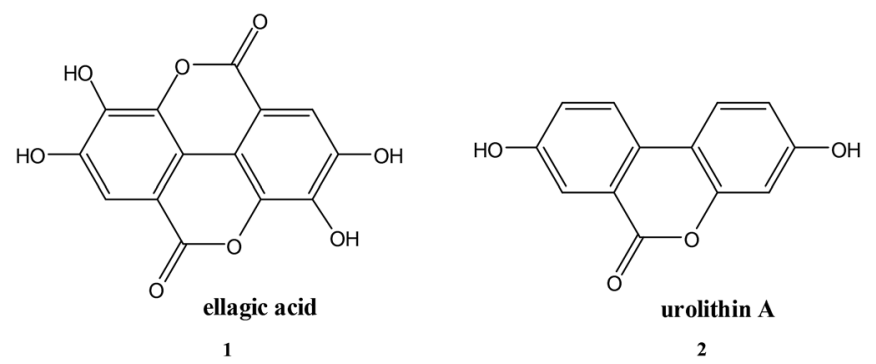

Ellagic acid (1) is a polyphenolic phytochemical ${ }^{15}$ present in various fruits and vegetables ${ }^{16}$ and of biological and pharmaceutical interest due to its antioxidant properties. ${ }^{17}$ Polyphenols play an essential role in plant physiology and also assist in the prevention of infection from plant pathogens. ${ }^{18}$ Ellagic acid has anti-inflammatory effects ${ }^{19}$ and has also been investigated for its antibacterial properties ${ }^{15,20}$. Ellagic acid (1) contains a $\delta$ lactone, which could act as an acylating agent, as well as acidic phenolic groups capable, by ionisation, of acting as the anionic binding to the active site positively charged residue, thus it

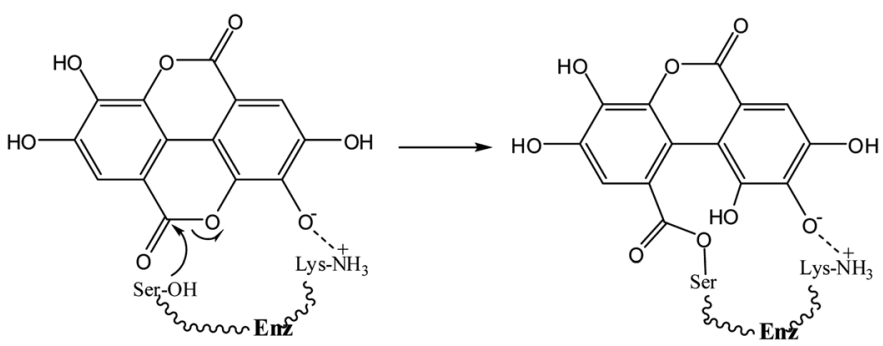

Scheme 1 
possesses the two fundamental requirements of an inhibitor of serine $\beta$-lactamases ${ }^{4}$ (Scheme 1). The reverse reaction to regenerate the enzyme is not favourable because of the low nucleophilicity of the phenol.

\section{Results and discussion}

The inhibition of SBLs by ellagic acid (1) was investigated using the rate of the enzyme catalysed hydrolysis of the antibiotic substrate cephalothin at $260 \mathrm{~nm}$ to measure the changing concentration of the active SBL during its time dependent inhibition. There are more than 100 CTX-M SBLs described and they are the most rapidly spreading family of $\beta$-lactamases in Europe and North America. ${ }^{21}$ The CTX-M-15 catalysed hydrolysis of cephalothin has a low $K_{\mathrm{m}}$ and a broad $\mathrm{pH}$-rate profile making it suitable to determine the rate of inhibition by ellagic acid and its $\mathrm{pH}$ dependence. Appropriate blanks containing the same reaction conditions but with no ellagic acid present were undertaken to ensure that enzyme activity was maintained during the time scales of the inhibition studies. The rate of SBL $(10 \mathrm{nM})$ inactivation at $\mathrm{pH} 7.0$ was exponential with time (Fig. 1) to generate pseudo-first-order rate constants $k_{\mathrm{i}}{ }^{\text {obs }}$ which in turn showed a first order dependence on the concentration of ellagic acid. The corresponding second-order rate constant for inactivation $k_{\mathrm{i}}=1.16 \times 10^{4} \mathrm{M}^{-1} \mathrm{~s}^{-1}$ demonstrates that ellagic acid (1) is a very effective inhibitor of the SBL.

This time dependence is indicative of a covalent reaction between ellagic acid and the enzyme. A UV scan of a 1:1 mixture of CTX-M-15 or TEM-1 SBL enzymes $(70 \mu \mathrm{M})$ and ellagic acid $(70 \mu \mathrm{M})$ showed a decrease in absorbance from 2.7 to 0.8 at $275 \mathrm{~nm}$ compatible with a reaction taking place between the enzyme and the ellagic acid.

Ellagic acid has four ionisable phenolic groups and which of the ions was responsible for enzyme inactivation was established by measuring the $\mathrm{pH}$ dependence of the rate of inactivation. The four $\mathrm{p} K_{\mathrm{a}}$ 's of ellagic acid in water at $25{ }^{\circ} \mathrm{C}$ are 6.45 , $7.45,9.61$ and 11.50 and a speciation plot (ESI $\dagger$ ) showed how the fraction of each ionic form varies with $\mathrm{pH}$, so, for example, at $\mathrm{pH} 7.0$ the fractions of $\mathrm{EH}_{4}, \mathrm{EH}_{3}{ }^{-}$and $\mathrm{EH}_{2}{ }^{2-}$ are $0.16,0.62$ and 0.22 , respectively. The $\mathrm{pH}$-dependence of the rate of hydrolysis

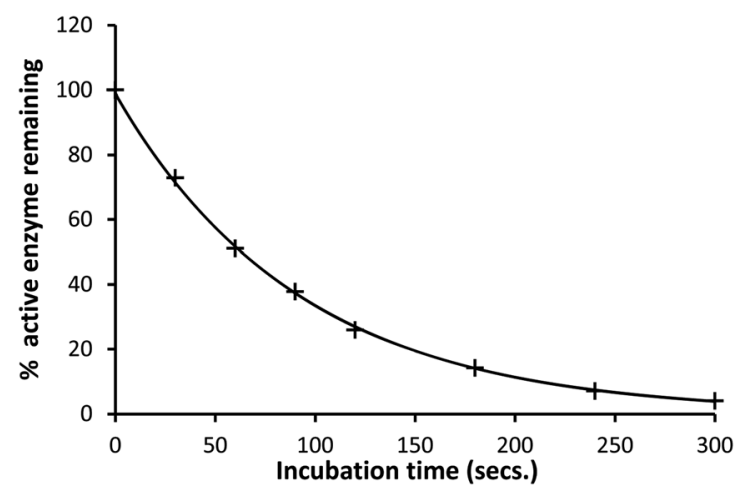

Fig. 1 Percentage active CTX-M-15 (10 nM) remaining after incubation with ellagic acid $(1 \mu \mathrm{M})$ in $\mathrm{pH} 7.0 \mathrm{HEPES}$ buffer $(0.10 \mathrm{M})$ at $30^{\circ} \mathrm{C}$ and $I=1.0 \mathrm{M}(\mathrm{KCl})$. of the substrate cephalothin by the SBL CTX-M-15 shows a typical broad bell-shaped profile corresponding to $\mathrm{p} K_{\mathrm{a}}{ }^{1}$ and $\mathrm{p} K_{\mathrm{a}}{ }^{2}=4.75$ and 8.95, respectively. Consequently, there is more than $93 \%$ active enzyme between $\mathrm{pH} 6$ to 8 and therefore the changes in the second order rate constants $k_{\mathrm{i}}$ for the inactivation of CTX-M-15 by ellagic acid at various $\mathrm{pH}$ levels (Fig. 2) reflect the activity of the ionic species of the inhibitor. It shows that the unionised species is inactive but both the mono- and di-anions are active. The values of the second-order rate constants for the two anionic species can be estimated from eqn (1), where $k_{\mathrm{i}}^{\text {tot }}$ is the observed second-order rate constant for inhibition, $\alpha$ and $\beta$ are the fractions of the mono-anion and dianion of ellagic acid present at different pHs, respectively, and $k_{\mathrm{i}}^{\mathrm{EH}_{3}{ }^{-}}$and $k_{\mathrm{i}}^{\mathrm{EH}_{2}{ }^{2-}}$ are the calculated second-order rate constants for inhibition by the mono-anion and di-anion of ellagic acid, respectively.

$$
k_{\mathrm{i}}^{\mathrm{tot}}=\alpha \times k_{\mathrm{i}}^{\mathrm{EH}_{3}^{-}}+\beta \times k_{\mathrm{i}}^{\mathrm{EH}_{2}^{2-}}
$$

The estimated second-order rate constant for inactivation of CTX-M-15 by the mono-anion $k_{\mathrm{i}}^{\mathrm{EH}_{3}{ }^{-}}=1.31 \times 10^{4} \mathrm{M}^{-1} \mathrm{~s}^{-1}$ and by the di-anion $k_{\mathrm{i}}^{\mathrm{EH}_{2}{ }^{2-}}=1.42 \times 10^{4} \mathrm{M}^{-1} \mathrm{~s}^{-1}$. The requirement for a negative charge on the inhibitor is compatible with that for substrates of SBLs ${ }^{4}$ and reflects its interaction with a positively charged residue (Lys-234) on the enzyme (Scheme 1). Of course, future work on the potential viability of using ellagic acid as an active ingredient for combatting antibiotic resistance would require pharmacological and toxicological studies.

Another indication of the importance of the acidic phenol in ellagic acid providing the anionic binding site is that the structurally similar $\delta$-lactone urolithin A (2) ( $\left.\mathrm{p} K_{\mathrm{a}} 7.5\right)$, but which lacks the geometrically appropriate phenolic residue, shows only modest inhibitory activity against CTX-M-15. Complete inactivation does not occur with $10 \mathrm{mM}$ urolithin A and CTX-M$15(10 \mathrm{nM})$ at $\mathrm{pH} 7.0$ and $30{ }^{\circ} \mathrm{C}$ with a $k_{\mathrm{i}}<50 \mathrm{M}^{-1} \mathrm{~s}^{-1}$.

Finally, the chemically more reactive $\beta$-lactone, but lipophilic, orlistat (3) which is one of the most effective inhibitors of

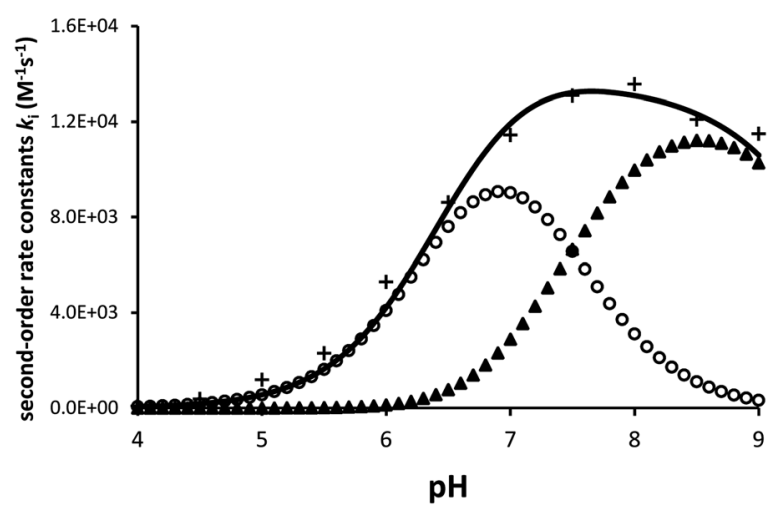

Fig. 2 The dependence of the second order rate constant $k_{\mathrm{i}}$ for the inactivation of CTX-M-15 (10 nM) by ellagic acid $(100 \mathrm{nM})$ on $\mathrm{pH}$ at $30{ }^{\circ} \mathrm{C}$ and $I=1.0 \mathrm{M}(\mathrm{KCl}) .+=$ observed $k_{\mathrm{i}}^{\text {tot }}, \mathrm{o}=$ calculated contributions of $k_{\mathrm{i}}$ for mono-anion and $\boldsymbol{\Delta}=$ that from $k_{\mathrm{i}}$ for di-anion of ellagic acid. The continuous line is the sum of the contributions of the two anions. 
lipase,$^{22}$ was tested as a SBL inhibitor. Orlistat $(10 \mathrm{mM})$ is only a weak inhibitor of the SBL CTX-M-15 in a $10 \%$ solution of acetonitrile at $\mathrm{pH} 7.0$ and $30{ }^{\circ} \mathrm{C}$ with a $k_{\mathrm{i}}=65 \mathrm{M}^{-1} \mathrm{~s}^{-1}$. Orlistat (3) is ca. 200-fold less effective as an inhibitor of CTX-M-15 than the chemically less reactive ellagic acid $(\mathbf{1})^{\mathbf{2 3}}$ highlighting the importance of intermolecular binding interactions between the inhibitor and the enzyme.

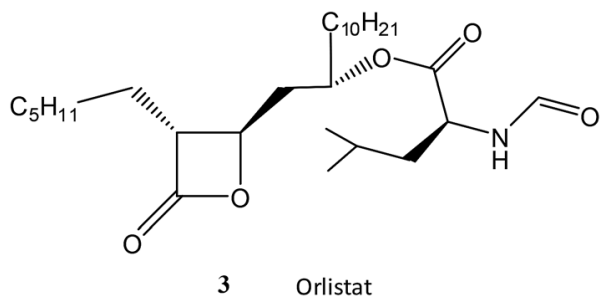

The class B $\beta$-lactamases are zinc-ion dependent and although ellagic acid can act as a chelating agent for metal ions, it showed no inhibitory activity against NDM-1 MBL up to a concentration of $10 \mathrm{mM}$.

\section{Conclusion}

Both the mono- and di-anions of ellagic acid are effective inhibitors of the SBL CTX-M-15 presumably by acylation of the active site serine with the phenolate anions providing binding to the active site Lys-234. The structurally similar $\delta$-lactone urolithin A but which lacks the geometrically appropriate phenolic residue, shows only modest inhibitory activity against CTX-M-15.

\section{Experimental}

The methods for detection of any inhibition of the $\beta$-lactamases were based on measuring the activity of the enzyme in catalysing the hydrolysis of cephalothin. Stock solutions of ellagic acid in $\mathrm{MeOH}$ and in acetonitrile (ACN) for orlistat and urolithin A were prepared. A $1 \mathrm{mM}$ ellagic acid (3.02 mg) in $1.0 \mathrm{~cm}^{3} \mathrm{MeOH}$ required sonicating for 20 minutes. The inhibition experiments for ellagic acid were conducted in buffers for the respective $\mathrm{pH}$ with $10 \% \mathrm{v} / \mathrm{v} \mathrm{MeOH}$ to aid solubility of (1). For example, at $\mathrm{pH}$ $8.5,20 \mathrm{~cm}^{3} \mathrm{pH} 8.5$ TAPS buffer $(0.1 \mathrm{M})$ with $10 \% \mathrm{MeOH}$ with ionic strength maintained to $1 \mathrm{M}$ with $\mathrm{KCl}$. For orlistat $(4.96 \mathrm{mg}$ ) was dissolved in $1 \mathrm{~cm}^{3} \mathrm{ACN}$ to give a $10 \mathrm{mM}$ stock solution. For urolithin A, $\left(2.28 \mathrm{mg}\right.$ ) was dissolved in $1 \mathrm{~cm}^{3} \mathrm{ACN}$ to give a $10 \mathrm{mM}$ stock solution. For both of these inhibitors, the inhibition experiments were conducted in pH 7.0 HEPES buffer (0.1 M) with $10 \% \operatorname{ACN}\left(18 \mathrm{~cm}^{3}\right.$, pH 7.0 HEPES buffer and $\left.2 \mathrm{~cm}^{3} \mathrm{ACN}\right)$ maintained to $1 \mathrm{M}$ ionic strength with $\mathrm{KCl}$.

Appropriate controls containing the same concentrations of solvent $(10 \% \mathrm{MeOH} / \mathrm{ACN})$ were used to ensure there was no effect on the activity of the enzyme. The hydrolysis of the antibiotic cephalothin was used to measure the concentration of the enzyme through inhibition/hydrolysis rates of the enzyme.

The enzyme was thawed slowly in melting ice and was added to the stock solution of the potential inhibitors. Samples were taken at intermittent timed intervals after incubation with various $\beta$-lactamases and pipetted into a $1 \mathrm{~cm}^{3}$ cuvette at $30{ }^{\circ} \mathrm{C}$ and cephalothin solution was added and the absorbance change at $260 \mathrm{~nm}$ recorded with time. The rates of hydrolysis of the cephalothin were determined from the initial slopes of absorbance against time. These initial slopes gave the percentage of active enzyme remaining and decayed exponentially with time indicative of a first-order kinetic process (Fig. 1).

The stability of the enzyme over the time periods used for the inhibition studies was determined from observing the initial slopes of the change in absorbance in the hydrolysis of cephalothin. This ensured that any change in the rate of hydrolysis reflects inhibition of the enzyme and not any other loss of activity of the enzyme.

The following buffers were used depending upon the $\mathrm{pH}$ required: $\mathrm{pH}$ 4-5: acetic acid, $\mathrm{pH}$ 5.5-6.5: 2-( $N$-morpholino) ethanesulfonic acid, $\mathrm{pH}$ 7.0-8.0: HEPES, $\mathrm{pH}$ 8.5-9.0 TAPS.

\section{Conflicts of interest}

There are no conflicts to declare.

\section{Acknowledgements}

We thank the Schofield group, University of Oxford for the gift of CTX-M-15.

\section{Notes and references}

1 M. S. Wilke, A. L. Lovering and N. C. J. Strynadka, Curr. Opin. Microbiol., 2005, 8, 525-533.

2 D. M. Livermore and N. Woodford, Trends Microbiol., 2006, 14, 413-420.

3 J. Davies and D. Davies, Microbiol. Mol. Biol. Rev., 2010, 74, 417-433; Y.-Y. Liu, Y. Wang, T. R. Walsh, L.-X. Yi, R. Zhang, J. Spencer and J. Shen, Lancet Infect. Dis., 2016, 16, 161-168; R. J. Fair and Y. Tor, Perspect. Med. Chem., 2014, 6, 25-26.

4 A. L. Fink and M. I. Page, in $\beta$-Lactamases, ed. J.-M.Frère, Nova, 2012, ch. 7, pp. 161-198.

5 M. I. Page and A. P. Laws, Chem. Commun., 1998, 1609-1617. 6 M. J. Crowder, J. Spencer and A. J. Vila, Acc. Chem. Res., 2006, 39, 721-728; Z. Wang, W. Fast, A. M. Valentine and S. J. Benkovic, Curr. Opin. Chem. Biol., 1999, 3, 614-622.

7 J. Brem, R. Cain, S. Cahill, M. A. McDonough, I. J. Clifton, J. C. Jiménez-Castellanos, M. B. Avison, J. Spencer, C. W. G. Fishwick and C. J. Schofield, Nat. Commun., 2016, 7, 12406.

8 M. I. Abboud, M. Kosmopoulou, A. Krismanich, J. W. Johnson, P. Hinchliffe, J. Brem, T. D. W. Claridge, J. Spencer, C. Schofield and G. I. Dmitrienko, Chem. - Eur. J., 2018, 24, 5734-5737.

9 D. T. King, S. Sobhanifar and N. C. J. Strynadka, The Protein Soc, 2016, 25, 787-803.

10 K. A. Toussaint and J. C. Gallagher, Ann. Pharmacother., 2015, 49, 86-89. 
11 C. T. Lohans, E. van Groesen, K. Kumar, C. L. Tooke, J. Spencer, R. S. Paton, J. Brem and C. J. Schofield, Angew. Chem., Int. Ed., 2018, 57, 1282-1285.

12 R. P. A. Brown, R. T. Aplin and C. J. Schofield, Biochemistry, 1996, 35, 12421-12432; C. Thierren and R. C. Levesque, FEMS Microbiol. Rev., 2006, 24, 251-262.

13 D. E. Ehmann, H. Jahic, P. L. Ross, R. F. Gu, J. Hu, G. Kern and S. L. Fisher, Proc. Natl. Acad. Sci., 2012, 109, 1166311668; T. A. Blizzard, H. Chen, S. Kim, J. Wu, R. Bodner, C. Gude and M. L. Hammond, Bioorg. Med. Chem. Lett., 2014, 24, 750-785; M. L. Monogue, S. Giavagnoli, C. Bissantz, C. Zampaloni and D. P. Nicolau, Antimicrob. Agents Chemother., 2018, 17, 2596-2617.

14 O. Lomovskaya, D. Rubio-Aparicio, K. Nelson, R. Tsivkosvski, D. C. Griffith, M. N. Dudley and D. Sun, Antimicrob. Agents Chemother., 2017, 61, 443-517.

15 D. A. Vettem and K. Shetty, J. Food Biochem., 2005, 29, 234266.
16 S. Corbett, J. Daniel, R. Drayton, M. Field, R. Steinhardt and N. Garrett, J. PeriAnesth. Nurs., 2010, 25, 214-220; C. Usta, S. Ozdemir, M. Schiarity and P. E. Puddu, Int. J. Food Sci. Nutr., 2013, 64, 907-913.

17 S. U. M. Talcott, S. T. Talcott and S. S. Percival, J. Nutr., 2003, 133, 2669-2674.

18 M. Daglia, Curr. Opin. Biotechnol., 2012, 23, 174-181.

19 D. C. Favarin, M. M. Teixeira, E. L. D. Andrade, C. D. F. Alves, J. E. L. Chica, C. A. Sorgi and A. P. Rogerio, Mediators Inflammation, 2013, 1-13.

20 E. Coppo and A. Marchese, Curr. Pharm. Biotechnol., 2014, 15, 380-390; L. Sanhueza, M. Wil, R. Montero, K. Maisey, L. Mendoza and M. Wilkens, PLoS One, 2017, 12, 1-15.

21 R. Bonnet, Antimicrob. Agents Chemother., 2004, 48, 1-14.

22 A. I. M. Gonzalez, E. A. Parrilla, A. G. D. Sanchez, L. A. de la Rosa, J. A. N. Gastelum, A. A. V. Flores and G. A. G. Aguilar, Food Technol. Biotechnol., 2017, 55, 519-530.

23 M. I. Page, Adv. Phys. Org. Chem., 1987, 23, 165-270. 